\title{
Aspectos produtivos do pinhão e a conservação da Araucaria angustifolia em uma comunidade rural ao Sul de Minas Gerais
}

\author{
Natália Reguera Carvalho ${ }^{1}$ \\ Viviane Santos Pereira ${ }^{2}$ \\ André Wagner Barata-Silva ${ }^{3}$
}

\begin{abstract}
RESUMO
Na Floresta Ombrófila Mista (FOM), encontra-se o pinhão, uma semente da Araucaria angustifolia, uma espécie florestal que está presente no Bioma Mata Atlântica. Esse bioma é rico em biodiversidade e ameaçado pelos seres humanos. A coleta e uso do pinhão representa oportunidade de renda, cultura, assim como oportunidade de conservação da espécie. Este artigo visou analisar os aspectos produtivos do pinhão, em uma comunidade rural localizada em Itamonte, Sul de Minas Gerais, relacionando-o à conservação da Araucaria angustifolia. A pesquisa classifica-se como qualitativa, do tipo descritiva. Para a coleta de dados, utilizou-se a observação participante, realização de entrevistas e análise documental. Durante a pesquisa, houve o convívio diário com a comunidade, uma vez que uma das autoras morou na comunidade rural durante seis meses, para desenvolver este trabalho, buscando se inserir e participar do cotidiano e nas atividades da comunidade. Inicialmente realizou-se um breve histórico sobre a relação entre a comunidade rural e as araucárias e, posteriormente, descrição e análise da cadeia produtiva do pinhão. Observou-se o pinhão como elemento presente e importante para a cultura local e para a geração de renda, assim como relevantes as inciativas da comunidade para favorecer a conservação da espécie. Salienta-se a necessidade de aumentar os esforços, para a conservação da espécie, assim como observou-se a necessidade de aperfeiçoamento e desenvolvimento da cadeia produtiva, no que se refere a aspectos como coleta, armazenamento, beneficiamento e comercialização.
\end{abstract}

Palavras-chave: Observação participante; sustentabilidade; cadeia produtiva.

\section{Productive aspects of the pinhão and the conservation of Araucária angustifolia in a rural community in southern Minas Gerais}

\begin{abstract}
The Araucaria angustifolia, also known as Parana Pine, is a critically endangered species of tree that produces an edible seed called "pinhao", found in the Atlantic Forest biome. This biome is rich in biodiversity and highly threatened by humans. The collection and use of pinhão represents an opportunity for income, cultural development as well as an encouragement for the conservation of those species. This article aimed to analyze productive aspects of the pinhão in a rural community located in Itamonte, south of Minas Gerais, relating them to the conservation of Araucaria angustifolia. This research is classified as qualitative, descriptive. The data collection was carried out through participant observation, interviews and document analysis. During the research there was daily contact with the community since one of the authors lived in the rural community for six months to develop this work, in order to achieve a deep understanding of local knowledge. Initially, there was a brief history on the relationship between the rural community and the araucaria and later description and analysis of the pinhão productive chain. The Pinhão was observed as actual and important element for local culture and local economy, therefore relevant to foment community initiatives towards the conservation of the species. The conservation of Araucaria angustifolia is extremely important, therefore the need to increase efforts to protect the species is emphasized. So, the improvement and develop the production chain in terms of aspects such as collection, storage, processing and commercialization is considered a key piece towards the conservation of the Araucaria angustifolia.
\end{abstract}

Keywords: Participant observation; sustainability; production chain.

${ }^{1}$ Graduação em Ciências Biológicas pela Universidade Federal de Lavras (UFLA), Lavras - MG

${ }^{2}$ Professora no Departameto de Administração e Economia na Universidade Federal de Lavras (UFLA)

${ }^{3}$ Graduação em Ciências Biológicas e em Agronomia. Mestrado em Desenvolvimento Sustentável e extensão Doutorando em Fitotecnia na Universidade Federal de Lavras (UFLA) 


\section{INTRODUÇÃO}

O pinhão é uma semente produzida pela Araucaria angustifolia, uma espécie florestal que ocorre no ecossistema denominado Floresta Ombrófila Mista, que faz parte do bioma da Mata Atlântica, considerado como produto da sociobiodiversidade dentro do contexto da Mata Atlântica. De acordo com Santos et al (2002), o pinhão é um alimento nutritivo e apreciado pelo homem e pela fauna. Seu consumo pela população brasileira é mais presente nas regiões Sul e Sudeste, sendo preparado principalmente assado ou cozido. Está presente nas mostras culturais e gastronômicas dessas regiões, em especial, nas tradicionais festas do pinhão.

A A. angustifolia chama atenção na paisagem e é relevante do ponto de vista cultural, ecológico e econômico. Considerado como de baixo impacto, a coleta e uso do pinhão representa opção econômica para as comunidades rurais, assim como potencial para a conservação da espécie e manutenção da Floresta Ombrófila Mista, também conhecida como floresta de araucária (SCHUSSLER, 2014).

A cadeia produtiva do pinhão é caracterizada como um sistema integrado, constituído por atores interdependentes, sendo considerada uma cadeia simplificada composta, sobretudo, por produtores/coletores, intermediários, centros de abastecimento, varejistas e consumidores. A cadeia do pinhão é conhecida como uma cadeia de atravessadores, os quais são responsáveis pelo armazenamento, transporte e distribuição do pinhão in natura. O pinhão é utilizado na alimentação humana, de animais domésticos e fauna silvestre e tem sua importância reconhecida enquanto produto dentro das estratégias para a conservação das florestas nativas (CERTI, 2012).

Seu consumo, quando aliado à extração sustentável, pode desempenhar papel importante para garantir a conservação da espécie, sendo também uma alternativa de renda à exploração predatória e ilegal de madeira da araucária (CERTI, 2012). Segundo Danner et al (2012), a madeira da araucária foi explorada de forma intensa e predatória em função de sua qualidade para construções e para fabricação de papel entre 1930 e 1990. Representava um importante produto para as exportações brasileiras e gerou uma rápida diminuição, em sua densidade populacional, assim como em sua distribuição geográfica. Restam $3 \%$ da cobertura original da floresta de araucária e, especificamente, em Minas Gerais, restam poucos fragmentos florestais. Por essa razão, essa espécie foi classificada como criticamente endêmica e, desde 2006, está presente na lista vermelha de espécies ameaçadas de extinção pela União Internacional para a Conservação da Natureza (THOMAS, 2013).

Diante da ameaça de extinção da espécie $A$. angustifolia, foi aprovada uma resolução do CONAMA 278/01 que suspendeu seu corte e sua exploração. Apesar de tal medida ter sido pensada, buscando favorecer a conservação da espécie, alguns autores acreditam que a proibição de seu corte em si gerou uma desvalorização econômica da espécie e proprietários rurais passaram a impedir a regeneração natural da A. angustifolia comprometendo a conservação da espécie (DANNER et al., 2012).

Todo este contexto ressalta a importância de se considerar a conservação da $A$. angustifolia sob uma perspectiva diversa, compreendendo a relação econômica, social, ecológica e cultural entre o pinhão, a araucária e as comunidades rurais, para analisar as potencialidades, limitações e oportunidades dentro da cadeia produtiva a fim de contribuir para com a sustentabilidade.

Este artigo visou analisar aspectos produtivos do pinhão, em uma comunidade rural, localizada em Itamonte, Sul de Minas Gerais, relacionando-o à conservação da Araucaria angustifolia. Buscou-se conhecer a realidade local, em termos culturais, sociais, ambientais e econômicos, para compreender a relação entre a comunidade e a cadeia produtiva do pinhão, durante a safra do ano de 2016, a fim de analisar a importância da araucária dentro dessa cultura, 
bem como as potencialidades e limitações relacionadas à conservação da espécie no contexto local para favorecer sua sustentabilidade.

\section{REVISÃO DE LITERATURA}

A Araucaria angustifolia é uma espécie florestal nativa que está presente no ecossistema denominado Floresta Ombrófila Mista (FOM), pertencente ao Bioma Mata Atlântica, um bioma muito rico e seriamente ameaçado (MINISTÉRIO DO MEIO AMBIENTE, 2006). Tendo uma madeira de alta qualidade a construções e à fabricação de papel a Araucaria angustifolia foi muito explorada, restando poucos fragmentos, principalmente no Sul do Brasil e em alguns fragmentos isolados nos estados de São Paulo, Minas Gerais e Rio de Janeiro. A região Sul de Minas Gerais faz parte do limite Norte de distribuição geográfica da espécie. Reconhecida como espécie ameaçada de extinção, desde 2001, a legislação brasileira, via Resolução 278/01 do CONAMA, impede a exploração da madeira de araucária nativa (DANNER et al., 2012). A exploração dessa madeira teve importante papel à sua ameaça de extinção fazendo com que o extrativismo se tornasse uma alternativa cada vez mais adotada.

A Araucaria angustifolia é popularmente conhecida como pinheiro brasileiro e possui arquitetura peculiar, beleza e porte grande das árvores adultas (DILLENBURG et al., 2009). De acordo com Silva e Miguel (2017), a Araucária angustifolia produz uma semente, conhecida como pinhão, que serve como fonte de alimento tanto para a fauna silvestre quanto para o ser humano, pois sua produção ocorre em época de escassez de recursos alimentícios na floresta. É um alimento rico e com propriedades medicinais, possuindo importância socioeconômica e cultural, haja vista festas do pinhão que ocorrem nos diversos estados brasileiros.

O pinhão representa um recurso da sociobiodiversidade, priorizado dentro do contexto da Mata Atlântica, assim como está relacionado à identidade cultural e à dimensão socioeconômica de comunidades envolvidas com a sua cadeia produtiva (BRASIL, 2009). Em estudo realizado por Silva (2006, p. 97), foi observada uma grande importância do pinhão para as comunidades rurais, como fonte de renda, sendo reforçada a necessidade de aliar "a valorização dos recursos florestais, o desenvolvimento de comunidades juntamente com a conservação dos remanescentes florestais". O extrativismo é uma atividade milenar e se refere à coleta de produtos naturais. Conhecer a cadeia produtiva do pinhão pode ajudar na compreensão de cada localidade e suas especificidades e no desenvolvimento de ações mais efetivas para a conservação da espécie aliada aos demais interesses da comunidade.

O marco legal para o início da coleta do pinhão, em âmbito nacional, é de abril a agosto de cada ano, denominado período de defeso. Geralmente os preços são maiores no início e final de safra, pela escassez de oferta do produto nesses períodos (CERTI, 2012). O período de defeso foi definido, para garantir alimento para a fauna e possibilitar a regeneração natural da espécie, sendo essas as duas questões ecológicas mais importantes relacionadas à "cata" do pinhão.

Segundo Amaral e Fichino (2014), existe uma discussão importante, no que se refere ao período de defeso do pinhão, pois desconsidera variações geográficas (espécie presente em seis estados do Brasil), temporais e as mudanças climáticas globais que influenciam sua época de maturação. A legislação que permite a coleta, a partir do dia 15 de abril, foi elaborada de acordo com os padrões climáticos, geográficos e ambientais da região Sul do Brasil. Isso se constitui uma grande problemática, visto que todas essas variáveis tendem a diferir entre as regiões do Brasil gerando épocas de maturação variáveis (DANNER et al., 2012).

No que se refere à estrutura da cadeia produtiva do pinhão, pode-se dizer que é bastante simplificada. Sua comercialização é realizada, principalmente in natura e na região de produção, pela sazonalidade de sua produção, elevada perecibilidade e falta de industrialização do pinhão, como acontece em outras amêndoas (DANNER et al., 2012). Além disso, existe carência de 
estudos de impacto socioeconômico, quando se considera a diversidade de estados em que as florestas de araucária estão presentes.

O pinhão é obtido principalmente por meio de coleta no solo e na árvore. A coleta do pinhão no solo ocorre após sua queda natural da araucária e a coleta do pinhão na árvore ocorre com a subida (escalada) do coletor na árvore e o desprendimento ativo da pinha. Sobre os principais atores envolvidos na cadeia do pinhão, mencionam-se os produtores, intermediários, centros de abastecimento, varejistas e consumidores.

Os produtores/coletores são agricultores (as) ou catadores (as) que ocupam parte do seu tempo em sua colheita. Os intermediários são os atravessadores, intermediando a saída do campo para o consumidor (transporte, armazenamento e distribuição). Os centros de abastecimento são pontos destinados à comercialização de produtos, nas principais cidades de cada Estado, sendo o principal acesso dos produtos aos mercados varejistas dos grandes centros urbanos. Os varejistas são principalmente os mercados e supermercados que vendem o produto aos consumidores finais (CERTI, 2012).

Alguns agricultores(as) e coletores realizam a comercialização direta via feira ou, por exemplo, em bancas na estrada. Porém nem sempre essa alternativa é viável por motivos diversos, tais como distância dos centros consumidores, baixa quantidade de produtos individualmente, falta de transporte. Nesse sentido, sua organização em cooperativas e associações poderiam viabilizar a incorporação dessa função na base da cadeia (CERTI, 2012).

Tanto a comercialização quanto a utilização dos recursos florestais para o consumo, relacionado ao extrativismo sustentável, pode ter papel fundamental para a conservação da espécie, mantendo a diversidade de animais e vegetais. Com o manejo sustentável em Florestas de Ombrófila Mista, potencializa-se também formas de relações sociais e associações que favorecem as comunidades e o ecológico (SILVA E MIGUEL, 2017).

\section{PROCEDIMENTOS METODOLÓGICOS}

Este artigo é um dos frutos do Trabalho de Conclusão de Curso intitulado "Estudo Socioambiental com foco na Cadeia Produtiva do Pinhão, a partir de uma visão de Conservação da Araucaria angustifolia, na comunidade Rural de Campo Redondo- Itamonte- Minas Gerais”.

Esta pesquisa classifica-se como qualitativa e do tipo descritiva. Para Oliveira (2008, p. 41), a pesquisa qualitativa se refere ao "processo de reflexão e análise de técnicas para a compreensão detalhada do objeto de estudo em seu contexto histórico ou segundo a sua estruturação". Na pesquisa do tipo descritiva, buscam-se observar, registrar, analisar, classificar e interpretar os fenômenos (ANDRADE, 2009).

Este estudo foi desenvolvido, em uma comunidade rural, localizada no bairro rural Campo Redondo (Figura 1), que pertence ao município de Itamonte/MG, estando localizada a 32 $\mathrm{km}$ do centro do município e conta com mais de 80 famílias cadastradas no posto de saúde comunitário. Itamonte se localiza ao Sul de Minas Gerais, próximo aos municípios de Itanhandu e Passa Quatro.

A comunidade rural de Campo Redondo faz parte da Área de Preservação da Serra da Mantiqueira (APASM) e está situada entre dois importantes parques: Parque Estadual da Serra do Papagaio e Parque Nacional de Itatiaia. A Serra da Mantiqueira compõe uma importante cadeia montanhosa, com altitudes acima de 2000 metros, que interferem sobre o clima da região. É considerada como uma grande reserva de água do planeta e possui remanescentes florestais do bioma Mata Atlântica com a presença de Floresta Ombrófila Mista (FOM) (DETZEL et al, 2018).

Revista Desenvolvimento Socioeconômico em debate v.7 n.2 (2021) 
Figura 1- Mapa da Localização do Bairro Rrural Campo Redondo, Itamonte/MG.

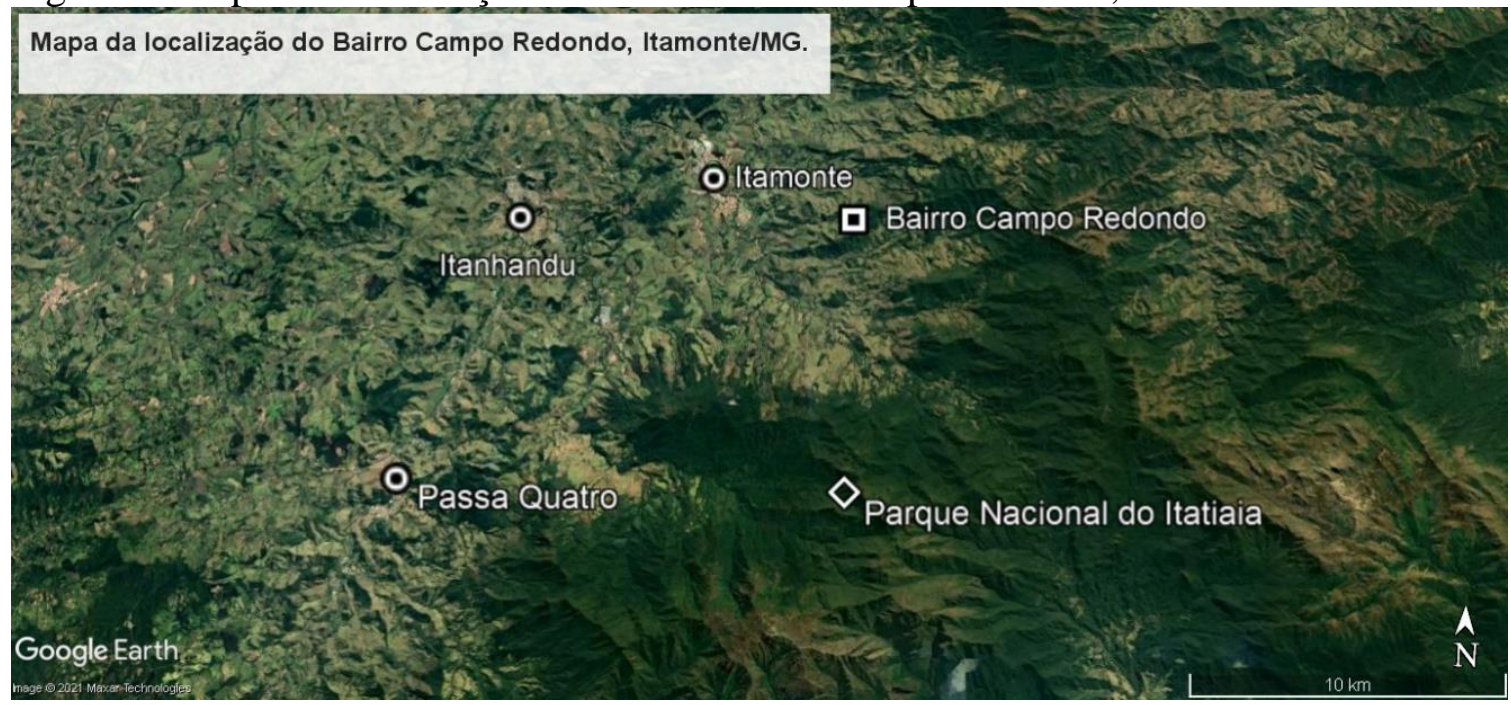

Fonte: Google Earth, 2021.

Para a coleta de dados, utilizou-se a observação participante, realização de entrevistas e análise documental. Durante a pesquisa, houve o convívio diário com a comunidade, uma vez que uma das autoras se mudou para a comunidade rural - durante seis meses, para desenvolver um Trabalho de Conclusão de Curso - buscando se inserir e participar do cotidiano e atividades da comunidade. O processo sistemático de observar, descrever e analisar foram empregados neste estudo com o intuito de obter melhor compreensão da cultura da comunidade e sua relação com as araucárias.

No primeiro mês, a observação teve característica mais descritiva e foram inciadas as entrevistas. A partir do segundo mês, desde a chegada à comunidade, houve maior receptividade e espaço para participar das atividades cotidianas, como sair com as mulheres para coletar pinhão, coleta de galhos e palhas, acompanhamento da dinâmica de compra dos pinhões da comunidade pelos pinhãozeiros, entre outras experiências e atividades junto à comunidade.

Durante a observação participante, foram sendo identificados aspectos considerados importantes, como a dinâmica da coleta do pinhão, como o pinhão e as araucárias eram utilizados, o processo de comercialização, o papel do pinhão em termos culturais, a conservação das araucárias entre outros aspectos.

A partir desses elementos, algumas observações foram anotadas no caderno de campo e outras observações foram gravadas e transcritas. As observações relatadas complementaram de maneira significativa as entrevistas e conversas informais de maneira que foi possível uma análise mais próxima à cadeia produtiva do pinhão na comunidade de Campo Redondo (Itamonte-MG). Foram realizadas 21 entrevistas com moradores da comunidade rural de Campo Redondo, sendo gravadas e transcritas. Para Ribeiro (2008), a técnica da entrevista permite ao pesquisador conhecer mais sobre a realidade estudada, possibilitando a interpretação de valores e atitudes que podem ser incorporadas aos resultados.

Inicialmente foi realizada uma caminhada pela comunidade com um membro da comunidade, agricultor familiar de 21 anos, que se dispôs a apresentar a comunidade, por meio de de uma entrevista informal gravada que seguia um roteiro pré-estabelecido, buscando reunir aspectos investigativos relacionados à cadeia produtiva do pinhão e à conservação da araucária, em termos culturais, econômicos e sociais. Segundo Alencar (1999), o roteiro constitui um conjunto de tópicos a serem abordados, durante uma entrevista, havendo liberdade para aprofundamento dos tópicos, por meio de questões que surgem, durante o diálogo entre o entrevistador e o entrevistado. 
O primeiro entrevistado cumpriu um papel de informante, dispondo-se a compartilhar elementos sobre a estrutura social, costumes e história da comunidade e também sugeriu contato com moradores que ainda poderiam contribuir com informações relevantes.

A partir dessas indicações, foram sendo realizadas as entrevistas semiestruturadas, em que surgiram novos elementos relacionados ao tema central ou referentes à contextualização de questões socioeconômicas, políticas e ecológicas da comunidade. Esses elementos foram analisados e incorporados, com o intuito de enriquecer a investigação social. Alencar (1999) argumenta que, em virtude do caráter circular da pesquisa qualitativa, as observações e análise de documentos ou entrevistas anteriores podem auxiliar o planejamento e adequações nas entrevistas futuras. A análise documental foi realizada, a partir de um livro sobre a história de Campo Redondo, escrito por um grupo de membros da comunidade, em um projeto de pesquisa de escola, disponibilizado por membros da comunidade.

A análise dos dados ocorreu a partir das observações, percepções, entrevistas e análise documental. A articulação de todos os elementos do trabalho de campo permitiu a construção da categoria aspectos históricos ligados à araucária e à comunidade, à categoria cadeia produtiva do pinhão e às reflexões sobre os resultados relacionando-os com os objetivos. De acordo com Ribeiro (2008), o pesquisador deve avaliar, classificar e categorizar as respostas, organizando-as de acordo com conteúdo e tema. Os dados foram analisados por meio dessa organização e categorização que possibilitou análise sistemática para se chegar à redação de resultados e conclusões, conforme GIL (2008).

\section{RESULTADOS E DISCUSSÃO}

Antes de adentrar na cadeia produtiva do pinhão, apresentam-se alguns elementos históricos relacionados às araucárias que fazem parte da comunidade de Campo Redondo. Ainda se observa na comunidade a presença de monjolo, paiol e bicas de água feitas, a partir da madeira de araucária, assim como chão das casas.

Outro elemento da araucária usado historicamente pela comunidade é o nó da araucária, inclusive para gerar renda. Antigamente o "nó de pinheiro", como referido pelos entrevistados, era vendido para quem se interessasse por material que proporcionasse uma boa e duradoura brasa, como era o caso dos padeiros da cidade.

A gente usava catar nó de pinheiro pra vender pra um padeiro que vinha lá de Itamonte comprar, ele dizia que pra assar pão não tinha melhor do que o nó do pinheiro. Se você for usar no fogão à lenha tem que até tomar cuidado pois pode até furá o cano da serpentina de tão forte a brasa (Entrevistada 2).

Mais recentemente, o nó do pinheiro tem sido utilizado para a confecção de artesanatos. No entanto o nó da araucária, por se tratar de uma estrutura interna que conecta o tronco aos galhos, é retirado depois da morte da árvore.

Pode-se observar também outra forma de utilização da araucária, para tingimento de lãs de ovelha. Por meio do cozimento do pinhão obtém-se uma cor arroxeada. Para tingir a lã, utilizam a casca e os fagulhos (estruturas acopladas ao pinhão). De acordo com as entrevistas, existem oito plantas utilizadas para o tingimento da lã. A produção de lãs pelas mulheres advindas da criação de ovelhas faz parte da história de Campo Redondo.

As mulheres eram as responsáveis por todo o processo para a confecção de cobertores de lã. Foi relatado por uma das entrevistadas que havia 50 fiandeiras, que produziam e vendiam novelos de lã, mas, durante o trabalho de campo, foram identificadas poucas mulheres que trabalham com essa lã e apenas uma, fiando, transformando lã em novelos. Ao longo dos anos, a atividade foi diminuindo e poucas pessoas dão continuidade à essa tradição. 
Outra forma de utilização da araucária, na cultura dos moradores de Campo Redondo, é a utilização dos galhos e palhas para acender fogão a lenha. As mulheres costumam coletá-los no chão após caírem naturalmente. Em vinte residências, onde foram realizadas as entrevistas, percebeu-se a utilização do fogão a lenha e a instalação de serpentina (que possibilita água aquecida para o interior da casa para banho, etc). Os galhos secos das araucárias são reconhecidos como muito bons para iniciar o fogo do fogão a lenha. Essas informações permitem perceber a araucária, abrangendo aspectos sociais e culturais, que reforça ainda mais a conservação de sua espécie, para além de sua importância ecológica e econômica.

Após esta breve contextualização, que traz alguns elementos históricos sobre a relação entre a comunidade e as araucárias, iniciar-se-á a apresentação dos resultados relativos à cadeia produtiva do pinhão. A coleta é a primeira etapa, dentro da cadeia produtiva do pinhão, conhecida como "cata do pinhão". Essa prática faz parte da cultura local e tem importante papel na complementação de renda para a comunidade de Campo Redondo, principalmente para as mulheres, assim como contribui para a segurança alimentar e qualidade de vida na época do inverno.

Eu acho a renda do pinhão muito importante, minha moto foi comprada com dinheiro de pinhão, a varanda da minha casa foi construída com dinheiro de pinhão, eu tô tirando minha carta de motorista com dinheiro de pinhão, então eu acho que é um complemento que ajuda e muito (Entrevistada 5).

É interessante ressaltar a importância da "cata" do pinhão como renda e como alimento que proporciona maior autonomia especialmente às mulheres, assim como contribui para a maior segurança alimentar da comunidade. E não somente aos adultos, como também às crianças, que já possuem uma relação interessante com a coleta do pinhão. As crianças participam da coleta de forma espontânea e sentem muito prazer nessa atividade. Realizam a "cata", em seus próprios ritmos, gerando-lhes inclusive uma renda utilizada para compras de itens que seus pais não teriam condições de comprar.

$\mathrm{Na}$ época do pinhão, costumo sair 3 vezes por dia pra catar, um dia minha filha quando era pequenininha, disse: "Mãe também vou catar pinhão", ai ela levava um saquinho de feijão e assim foi indo, eu deixava os pinhões que ela catava separados e pesava separado vendia e dava o dinheiro dela, então o meu filho mais novo começou a se interessar também, juntos eles conseguiram juntar R\$: 400 e decidiram comprar um tablet (Entrevistada 5).

Apesar da importância da coleta do pinhão, enquanto renda complementar, ela é uma atividade que agrega pouco valor. O produto é normalmente vendido in natura. Não há investimento para sua coleta nem em equipamentos de proteção. As catadoras reutilizam sacos, como os de arroz (saco de $5 \mathrm{~kg}$ ) ou de farelo de milho (saco de $60 \mathrm{~kg}$ ).

Eu tinha 5 anos quando comecei a catar pinhão com minha mãe, na época vendia o pinhão por R\$: 0,10 a R \$: 0,20/kg. Quando a gente é criança não aguenta andar muito e nem carregar muito peso nas costas, então a gente costumava catar na nossa propriedade, quando eu tinha uns 12 anos já ia mais longe catar pinhão, ia pra Berta, um bairro vizinho daqui e também nas propriedades dos meus avós que é um pouco longe também (Entrevistada 3 ).

Por volta dos anos de 2007, as crianças ajudavam mais nas coletas, para complementar a renda em casa, principalmente nas famílias de baixa renda. Nessa época, o pinhão era comprado das famílias por R \$ 0,10/kg e, segundo relato pelos entrevistados, percebeu-se uma valorização no preço do pinhão. Isso estimulou a atividade da "cata" e contribuiu para a melhoria na qualidade de vida. 
Acho que a renda proveniente do pinhão é importante para as crianças, porque catar pinhão pra eles é uma brincadeira, até hoje. É o primeiro dinheiro que eles têm, deles. Eu vejo meus sobrinhos, começa a época do pinhão, e ele catam o pinhão. Quando tem preguiça, ninguém é obrigado a catar, cata porque quer. E eles vendem, o dinheiro é deles, pode ser a criança mais jovem. Na minha época parte do dinheiro do pinhão era pra ajudar em casa, porque naquele tempo era muito mais difícil, precisava mesmo ajudar em casa, mas a gente ganhava uma parte nossa. E aí complementa a renda naquela época do pinhão. Então, é o primeiro dinheiro, vamos dizer, das crianças aqui de Campo Redondo (Entrevistada 9).

Observou-se que, na cultura da comunidade rural de Campo Redondo, prevalece a coleta dos pinhões caídos naturalmente no chão. As mulheres e crianças costumam sair diariamente, de 1(uma) a três vezes por dia, em função da disponibilidade de pinhões caídos.

Aqui em Campo Redondo a gente costuma coletar só pinhão que estão caídos no chão, só quando a gente ia catar na Berta e não tinha nada no chão a gente costumava trepar no pinheiro, chacoalhar quando o pinheiro era baixo, quando era alto a gente cutucava com bambu, mas isso faz atrapalhar o processo do próximo ano e então diminui a produtividade do próximo ano, então fazendo isso a gente acaba agredindo o pinheiro, machucando os galhos. Quando a gente vai catar já começou o processo pro próximo ano, então quando a gente chacoalha, essas pinhas pequenas que estão em desenvolvimento acabam caindo também e aí no outro ano não vamos ter aquelas pinhas pra catar" (Entrevistada 3).

Ao longo do trabalho de campo, foi relatado que alguns homens escalam as araucárias, para chacoalhar os galhos, a fim de que as pinhas que estão madurando caiam, mas essa prática não foi observada durante essa safra do pinhão. Entrevistados comentaram que essa prática era bastante comum no passado, mas tem diminuído nos últimos anos. Tanto as observações quanto as entrevistas apontaram que o trabalho permanente de conscientização ambiental, desenvolvido pela escola municipal, tem papel importante para a diminuição de práticas prejudiciais à conservação da espécie. Com o tempo, a própria comunidade passou a perceber que a prática de chacoalhar os galhos das araucárias prejudicavam ou comprometiam seu desenvolvimento.

"Tem molecada que vem e sobe no pinheiro pra derriçar, cutuca com bambu e aí acaba com a pinheira né. Mas hoje acontece menos, já foi pior, os próprios donos dos terrenos que têm pinheiro ficam na vigia pra não deixar acontecer. Aqui o povo tem medo disso, derrubar as pinhas porque muita gente é contra aqui, então o povo daqui mesmo denuncia, pra não derrubar" (Entrevistado $6)$.

Sobre as dificuldades comentadas, durante a atividade de coleta do pinhão, observouse que a presença de mato alto atrapalha a coleta, além disso, podem ocorrer pequenos ferimentos em suas mãos, além de existir o risco de raios e tempestades e o risco de serem picados por cobras, aranhas, abelhas, etc. Na safra de 2015, uma jovem afirmou que teve a mão queimada por uma taturana que lhe provocou febre e mal-estar. Na safra de 2016, houve dois relatos sobre esses riscos e foi comentado que uma mulher foi picada por abelha e um grupo de mulheres presenciou um raio que caiu em um pinheiro muito próximo a elas.

Cabe ressaltar que a prática da "cata" do pinhão costuma ser realizada de forma coletiva pelas mulheres juntamente com as crianças. Elas se organizam para saírem juntas, nos locais mais distantes e, nesse caminho, vão se distraindo, interagindo, divertindo-se, conversando sobre assuntos diversos, gerando um importante espaço de socialização e união em meio a essa atividade. É comum coletar pinhão fora de suas propriedades e até mesmo em bairros vizinhos.

Normalmente elas coletam e juntam em sacos com até $60 \mathrm{~kg}$ ou deixam os sacos escondidos para serem recolhidos depois. Durante a "cata", toma-se o cuidado de coletá-los semterra, mato ou outras sujeiras vindas do solo e também sem fagulhos (estrutura acoplada às sementes na formação da pinha). 
Na comunidade de Campo Redondo, a maioria das propriedades são pequenas, possuem gado leiteiro e pastagem. Houve relato de associação entre presença de araucárias e diminuição na produção de leite o que pode influenciar o não plantio e desenvolvimento de mudas de araucárias nas propriedades.

É muita palha que dá debaixo do pinheiro, essa palha mata a grama e o capim, e pra muita gente a fonte de renda é a vaca que precisa desse capim pra comer, então quando tem araucária numa propriedade pequena, diminui o espaço de pasto, aí eles não querem. Aqui graças a Deus não tem esse problema, tem muito espaço pra vaca. Mesmo assim, tem muita gente que tem onde plantar e não planta, só quer catar, sai pegando pinhão no terreno dos outros, sai derrubando pinhão, fazendo um estrago. Por isso eu achei o projeto da escola uma maravilha, porque as crianças já aprendem desde pequenas como tratar dos pinheiros e ao mesmo tempo tirar sustento disso. Depois desse projeto da escola acho que deu uma aliviada, hoje é mais difícil ver gente trepando e cutucando as pinheiras (Entrevistada 5).

Somente em duas propriedades observou-se o interesse em plantar araucárias e a justificativa relaciona-se à percepção de beleza da espécie, assim como a importância de sua conservação pela ameaça de extinção. Foi relatado que um morador da comunidade (vindo do Rio de Janeiro) encomendou 1000 mudas de um outro morador para plantar em seu terreno. Porém, de acordo com o entrevistado 20 (que era produtor de mudas), os membros da comunidade não têm interesse em comprar e nem de plantar (mesmo quando as mudas são doadas). Este contexto aponta a necessidade de maiores reflexões e incentivos sobre a produção e plantio de mudas visando contribuir com a conservação da espécie.

Aqui é muito difícil quem planta. Não planto porque demora muito pra crescer e dar pinhão. Também às vezes você planta muito e dá mais pinheiro macho, que não dá pinhão (Entrevistado 6).

Esse tipo de relato é comum na comunidade de Campo Redondo. Diante deste contexto, observa-se a necessidade de serem construídas ações, políticas públicas e incentivos fiscais para a conservação da Araucaria angustifolia, ainda mais que essa espécie está ameaçada de extinção.

Após a coleta, normalmente, é realizada a seleção do pinhão, com o intuito de retirar os pinhões estragados, malformados etc e essa seleção tem o objetivo de ofertar um produto com mais qualidade e obter sua valorização (AMARAL E FICHINO, 2014). Porém, em Campo Redondo, os (as) catadores(as) não têm o costume de selecionar os pinhões após a coleta. Observou-se que eles costumam vender a preço baixo o produto in natura ao "pinhãozeiro" que seleciona e vende ao varejo. Em 2016, o pinhãozeiro pagou entre $\mathrm{R} \$ 1,00$ a $\mathrm{R} \$ 1,50$ por kilo do pinhão e de $\mathrm{R} \$ 0,10$ a $\mathrm{R} \$ 0,15$ por kilo para algum morador reunir os pinhões da comunidade, que são recolhidos em seu caminhão.

De acordo com o entrevistado 21, o pinhão de Campo Redondo é considerado pelo pinhãozeiro o mais limpo da região, pois ele também é responsável por comprar pinhões nas comunidades do entorno. Isso facilita o processo de seleção dos pinhões, que ocorre no município de Virgínia. Após seleção, os pinhões são ensacados (sacos de 20kg) e vendidos para outros atravessadores ou atacadistas, chegando aos supermercados de São Paulo.

Juntar pinhão pros caminhoneiros é uma atividade que compensa, por exemplo aqui a diária por um dia de trabalho é 40 reais, juntando pinhão chega a dar 200 reais por dia, mas também é cansativo, tem vezes que começa às 6 da manhã e termina 8 da noite. Isso porque aqui a gente não faz o trabalho de limpar o pinhão, do jeito que vem do povo ele leva. Eles falam que quando chegam lá em Virginia, jogam o pinhão na água pra ver se dura mais tempo, também pra limpar, depois eles tiram da água escorrem e separam em sacos de $20 \mathrm{~kg}$ (Entrevistado 6). 
Após seleção, os pinhões geralmente são armazenados até seu escoamento. Segundo Amaral e Fichino (2014), o pinhão deve ser armazenado em câmaras frias (temperatura a $4^{\circ} \mathrm{C} \mathrm{e}$ umidade relativa de $89 \%$ ), pois perde água e brota com facilidade, já que ele é uma semente. Isso dificulta sua viabilidade comercial. Porém o investimento em câmaras frias, para o armazenamento dos pinhões, não é acessível aos catadores(as) que acabam optando por vendê-los a um baixo preço. Durante o trabalho de campo, observou-se a utilização de técnicas em curto prazo, para a conservação do pinhão, evitando que ele brote e ataque de animais. Deve-se lavar as sementes em agua corrente e deixá-las secar ao sol. Após isso, são ensacadas e mantidas em local fresco e arejado.

Em Campo Redondo, o pinhão é armazenado em sacos de 60kg, que são fechados e mantidos em paiol (local geralmente arejado e protegido do ataque de animais). Como essa forma de armazenamento não garante a durabilidade do produto, os catadores precisam vendê-lo rapidamente. Vários entrevistados afirmaram que, quando novos, os pinhões possuem sabor, aspecto e textura melhor, assim que são coletados. Além disso, com o passar dos dias, eles começam a secar e ficam mais leves. Todos esses fatores colaboram para que se busque a venda $o$ mais breve possível.

Esses aspectos têm limitado a comunidade a conseguir um valor mais elevado no pinhão, pois eles preferem vender pelo preço oferecido pelos pinhãozeiros que correr o risco de não vender. Segundo Certi (2012), geralmente, é o atravessador (no caso deste estudo, o pinhãozeiro) que intermedia a saída do pinhão do campo até o consumidor, pagando à vista e agregando maior valor a essa cadeia produtiva. Na safra de 2016 de Campo Redondo, o pinhão foi comercializado por $\mathrm{R} \$ 1,00 / \mathrm{kg}$ (chegando a $\mathrm{R} \$ 1,50$ no início da safra). O valor final do pinhão em supermercados de São Paulo variou de $\mathrm{R} \$ 7,95 / \mathrm{Kg}$ a $\mathrm{R} \$ 12,00 / \mathrm{kg}$.

A renda obtida pelos catadores da comunidade de Campo Redondo, durante a safra do pinhão, girou em torno de $\mathrm{R} \$ 300$ a $\mathrm{R} \$ 2000$ a depender da disponibilidade de tempo para a coleta e da abundância do pinhão. No que se refere ao beneficiamento e subprodutos, na comunidade de Campo Redondo, foi observada somente a venda de bombons de pinhão por dois jovens que trabalham juntos como forma de agregação de valor.

Eu faço bombom de pinhão há 5 anos, e faz só dois anos que comecei a trabalhar junto com uma sócia. Nóis mesmo que coleta o pinhão. A gente faz todo o processo: cata, carrega, selecionamos os maiores pinhões, cozinhamos e descascamos. Ano passado por exemplo, eu cozinhei um saco de pinhão $(50 \mathrm{~kg})$, usei parte pras receitas e congelei o resto, aí deu certo, o pinhão durou bastante. Gasto uma hora pra fazer uma receita que rende 24 bombons que eu vendo por $\mathrm{R} \$: 1,50$ cada. Ano passado nos investimos R\$: 200 na compra dos ingredientes e no final rendeu R\$: 2000 de lucro, que foi dividido entre eu e minha sócia (Entrevistado 12).

Observou-se que o bombom se tornou uma importante oportunidade de geração de renda, mas que ainda precisa ser desenvolvida quer seja em aspectos relacionados à divulgação, quanto de infraestrutura e atendimento à legislação sanitária, visando à construção de canais de comercialização.

Observa-se a necessidade do desenvolvimento de subprodutos do pinhão, como para sua comercialização, buscando inclusive meios de incentivos dentro das legislações que incluem o pinhão, como produto da sociobiodiversidade, coerente com as necessidades da população local e em articulação com a valorização e conservação da araucária.

Um possível caminho a ser construído seria via à já existente, Associação dos produtores rurais de Campo Redondo (APRUCARE), assim como o desenvolvimento de uma cooperativa. Mas essa atuação de forma coletiva precisaria ser articulada, pois há membros da comunidade (a exemplo de uma das entrevistadas) que mencinaram não se sentirem à vontade em vender bombom de pinhão, já que já existem duas pessoas que realizam a venda e acreditam que isso poderia causar desgaste nas relações dentro da comunidade. Outras possibilidades podem ser 
pensadas, a partir do diálogo e de interesses em comum, buscando ações coletivas e organizadas para impulsionar e promover o crescimento da atividade em questão.

Apesar de haver o potencial, para agregar valor ao pinhão, por meio de bombons ou outros produtos dele derivados ou mesmo para sua comercialização in natura, observaram-se dificuldades em construir alternativas de comercialização. Com o trabalho de campo, observou-se maior interesse em comercializar o pinhão in natura e receber o dinheiro de imediato que se arriscar a receber preço melhor depois.

Por meio de relatos e observações, os moradores estão mais interessados em receber o dinheiro, na hora da venda, pois têm receio de não recebê-lo depois, o que dificultaria processos coletivos de organização.

Aqui em Campo Redondo se o povo se organizar dava pra vender direto por um preço muito melhor, mas ninguém tem a iniciativa, porque é uma coisa diferente, o povo prefere não mexer com aquilo, aí eles acabam sem a informação de que tem um jeito de vender o pinhão por um preço melhor e ficam acomodados. O povo daqui não tem proporção do quanto o produto pode ser melhor vendido, que tem meios pra isso, se o produto for trabalhado, limpo, organizado e aí dá até pra conseguir nota de produção rural. Se você tirar a nota como produtor rural tem os benefícios, por exemplo, você não precisa pagar a taxa pra comercializar, e é legal, diferente dos caminhoneiros que não podem tirar essa nota, não são eles os produtores né (Entrevistado 1).

Sobre o marco de defeso, para a coleta na comunidade de Campo Redondo, notou-se que, durante a safra, que foi acompanhada pelo trabalho de campo, os pinhões começaram a cair das árvores, a partir de 22 de fevereiro, momento em que os moradores iniciaram a coleta somente para a alimentação. A comercialização foi observada, a partir da segunda quinzena de março. Observou-se que algumas pessoas da comunidade de Campo Redondo não se sentem afetadas diretamente pelo período de defeso do pinhão. Isso se deve ao fato do pinhãozeiro ser a pessoa mais sujeita à multa e apreensão de carga, pois é ele quem transporta a carga.

Embora não tenha sido identificada uma grande demanda pela mudança de data, para o início do defeso, observou-se que esse aspecto limita a obtenção de maior renda, uma vez que grande parte dos pinhões já estão caindo naturalmente antes do dia 15 de abril. Dez entrevistados acreditam que poderia ser interessante que o início do período de defeso do pinhão, em sua região, poderia ser entre $1^{\circ}$ e 15 de março.

Esse ano a revendedora que a gente vende todos nossos produtos, veio e pediu $230 \mathrm{~kg}$ de pinhão pagando $\mathrm{R} \$ 4,00 / \mathrm{kg}$ de pinhão, porque tinha gente interessada em comprar, mas aí era antes do dia 15 de abril, e a gente sabe que é proibido vender antes, que dá multa se apreenderem. Só que nesse meio tempo dá muito pinhão. Acabou que não vendemos, só depois do dia 15 mesmo, que é uma data que já caiu a maior parte do pinhão e aí já não e tão favorável pra comercializar (Entrevistado 1).

Cabe ressaltar que cada região em que haja coleta do pinhão possui padrões ambientais diferenciados, com diferentes dinâmicas, inclusive sobre a época de maturação das sementes. Além do fator ambiental, existe ainda o fator sociocultural que também difere, inclusive entre as comunidades rurais do município de Itamonte. Desta forma, seriam necessários estudos ambientais e sociais que pudessem analisar o caso dessa região.

\section{CONSIDERAÇÕES FINAIS}

Para se conhecer e analisar a cadeia produtiva do pinhão, foi importante fazer parte do cotidiano da comunidade, participando de suas atividades e construindo relações de amizade e confiança. Foi possível compreender melhor a dinâmica local, observando diversos aspectos de sua realidade, tais como culturais, ambientais, econômicos e sociais, o que possibilitou perceber as particularidades da cadeia produtiva do pinhão na comunidade e a relevância da Araucaria 
angustifolia para a vida da comunidade estudada. Apesar disso, considera-se como limitação deste estudo o acompanhamento de apenas uma safra, sendo necessário acompanhamento de outras safras e épocas do ano para compreender melhor a realidade local.

As araucárias estão presentes, na história da comunidade, em sua paisagem, construções, artesanatos, complementando renda, em sua alimentação, enfim, no seu dia a dia. A cultura da "cata" pinhão representa alternativa de renda, especialmente para as mulheres, promovendo maior autonomia e qualidade de vida, assim como representa um importante espaço de socialização e de proximidade.

Na comunidade de Campo Redondo, a atividade de coleta do pinhão requer principalmente disponibilidade de tempo, não necessitando de investimentos financeiros das pessoas para a sua realização. A seleção e armazenamento são feitos de forma simples e, como o pinhão é vendido principalmente in natura aos atravessadores, há pouca agregação de valor ao produto. Mesmo assim, sua comercialização foi identificada como importante para a fonte de renda complementar. As inciativas com geração de subprodutos do pinhão podem ser promissoras, pois representam estratégias importantes para a agregação de valor.

$\mathrm{O}$ aperfeiçoamento da seleção, armazenamento e beneficiamento aliado à inserção, em cadeias curtas de comercialização, poderia ser uma alternativa para a valorização dos produtos da comunidade e da própria espécie. Nesse sentido, o fortalecimento de formas coletivas de organização poderia construir caminhos para essa valorização.

Apesar de serem percebidos iniciativas da comunidade, para a conservação da Araucária angustifolia, observa-se a necessidade de elas continuarem. A análise da cadeia produtiva do pinhão possibilitou perceber a necessidade de maior sensibilização e conscientização da comunidade sobre a sua conservação, sua importância para a biodiversidade e para os moradores da comunidade. Nesse sentido, a continuidade de pesquisas e ações junto à comunidade torna-se fundamental.

\section{REFERÊNCIAS}

ALENCAR, E. Introdução a Metodologia de Pesquisa Social, Universidade Federal de Lavras, 1999.

AMARAL, M. M.; FICHINO, B. S. Construção participativa de diretrizes para o manejo sustentável do pinhão (Araucária Angustifolia) a partir de uma visão da conservação da floresta com araucária e do uso do pinhão, Conselho Nacional da Reserva da Biosfera da Mata Atlântica, Caderno n. 43, 2014.

ANDRADE, Maria Margarida de. Introdução à metodologia do trabalho científico: elaboração de trabalhos na graduação. 9.ed. São Paulo: Atlas, 2009.

BRASIL. Plano Nacional de Promoção das Cadeias de Produtos da Sociobiodiversidade, 2009. BRASÍLIA: MDA/MMA/MDS. Acesso em 10 de fev. de 2016. Disponível em: < https://bibliotecadigital.seplan.planejamento.gov.br/bitstream/handle/123456789/1024/Plano\%20 Sociobiodiversidade.pdf? sequence $=1 \&$ isAllowed $=\mathrm{y}>$.

CERTI - Centro de Referência em Tecnologias Inovadoras. Diagnóstico das Cadeias Produtivas do Pinhão e da Erva-Mate. In: Análise Integrada das Cadeias Produtivas de Espécies Nativas da Floresta Ombrófila Mista e seu impacto sobre este Ecossistema. Fundação Grupo Boticário, vol. 1, fev. 2012. 
DANNER, M. A.; ZANETTE, F.; RIBEIRO, J. Z. O cultivo da araucária para produção de pinhões como ferramenta para a conservação. Pesquisa Florestal Brasileira. v. 32, n. 72, p. 441-451, 2012.

DETZEL, Valmir Augusto; BALDIM, Matheus Morganti; CIT, Cristiano; LAMBERTI, Sandy Plassmann. Instituto Chico Mendes de Conservação da Biodiversidade. Plano de manejo da Área de Proteção Ambiental da Serra da Mantiqueira. Detzel Consultores Associados S/S EPP. Brasília, 2018. p. 371.

GIL, A.C. Métodos e técnicas de pesquisa social. São Paulo. Atlas. 2008.

MINISTÉRIO DO MEIO AMBIENTE. O Corredor Central da Mata Atlântica: Uma nova escala de conservação da biodiversidade. Conservação Internacional \& Fundação SOS Mata Atlântica, 2006.

OLIVEIRA, M. M. de. Como fazer pesquisa qualitativa. 3. ed. Petrópolis: Vozes, 2008. 181p. RIBEIRO, E. A. A perspectiva da entrevista na investigação qualitativa. Evidência, Araxá, n. 4, p. $129-148,2008$

SANTOS, A. J.; CORSO, N. M.; MARTINS, G.; BITTENCOURT, E. Aspectos produtivos e comerciais do pinhão no Estado do Paraná. Curitiba: Revista Floresta, v.32, n.2, 2002. 163-169

SILVA, C. V. Aspectos da obtenção e comercialização de pinhão na região de Caçador - SC. 2006. Dissertação (Mestrado em Recursos Genéticos Vegetais) - Universidade Federal de Santa Catarina, Santa Catarina, 2006.

SILVA, C. V. da; MIGUEL, L. de A. Os canais de comercialização do pinhão e seus agentes, em São Francisco de Paula, RS. Floresta, Curitiba, PR, v. 47, n. 4, p. 489 - 500, out. / mar. 2017.

SCHUSSLER, Glauco. CONSERVAÇÃO PELO USO DA ARAUCARIA ANGUSTIFOLIA (BERTOL.) KUNTZE: análise de aspectos produtivos do pinhão e de interações com a fauna em diferentes fitorregiões do sul do Brasil. Florianópolis, SC, 2014. 318 p. (Tese)

THOMAS, P. Araucaria angustifoli: The IUCN Red List of Threatened Species, 2013. Disponivel em: < http://dx.doi.org/10.2305/IUCN.UK.2013-1.RLTS.T32975A2829141.en> . Acesso em: 29 de janeiro de 2018. 